\title{
Tidal Current Energy Resource Assessment Technique and Procedure Applied in Western Coastal Region, South Korea
}

\author{
Chul Hee Jo, Su Jin Hwang and Kang Hee Lee \\ Department of Naval Architecture and Ocean Engineering, Inha University, Incheon 402-751, South Korea
}

Received: December 16, 2014 / Accepted: February 02, 2015 / Published: April 30, 2015.

\begin{abstract}
After the nuclear power plant accident in Japan, Korean government has set the national goal to produce the electricity by renewable energy sources up to $11 \%$ by 2035 which is not easy to achieve without ocean energy development. The demand on the clean energy supply has been increased recently and there are many renewable energy development projects and plans announced worldwide. The ocean energy can be produced from tidal current, wave, tidal barrage and ocean thermal sources. The first step is to estimate the resource assessment for each energy source. There are several assessment methods introduced from IEA (International Energy Agency), IRENA (International Renewable Energy Agency), NREL (National Renewable Energy Laboratory), EU ERENE (European Community for Renewable Energy), Bonn University, DLR (German Aerospace Center), etc.. Even these known methods have some sort of similarity; there are different definitions and classifications among them. In this paper, the four-step energy potentials are defined and introduced as theoretical, geographical, technical and market potentials. The theories for each step are presented for ocean energies together with clear definitions. As the tidal current energy research and development are active in Korea having very strong tidal current speed along the west and south coastal regions, the detail procedure for each step of energy potential assessment is introduced for tidal current energy. The paper will illustrate the case study of tidal current power assessment in western coastal region, South Korea with highlighting the key aspects in determining the resource potentials.
\end{abstract}

Key words: TCP (tidal current power), resource assessment, API (averaged power intercepted), tidal current farm planning.

\section{Introduction}

The ocean energy has great advantages over other renewable energies due to the high energy density and wide area and reliability. Among ocean energies, tidal energy is characterized as the continuous, reliable and predictable clean energy. Also the density of sea water is much higher than air, a tidal turbine can produce about 850 times more than the same size wind device. Another advantage of tidal energy is that it can estimate the power production exactly knowing the cycle of high and low tidal periods. However, even tidal barrage has the same advantages like tidal current power, several tidal barrage construction projects over the world have been cancelled or postponed due to the

Corresponding author: Chul Hee Jo, professor, research field: ocean engineering. E-mail: chjo@inha.ac.kr. environmental impacts to the region. Tidal barrage plant needs quite a massive dams to close the estuary for the reservoir keeping water that can be released during low tide trough the turbine. In this reason, even there are suitable sites with the maximum $10 \mathrm{~m}$ tidal range on the west coast in Korea, several tidal barrage construction plans have been delayed against the environmental issues.

Having around 3,600 islands along the costal line together with high tidal range, there are many attractable and exploitable sites for tidal current energy in Korea. In Incheon, a 200 MW tidal current farm project has been launched where there is the maximum current speed of $3 \mathrm{~m} / \mathrm{s}$. In Jeolla Province, several tidal current farm projects; $260 \mathrm{MW}, 150 \mathrm{MW}, 300 \mathrm{MW}$, $100 \mathrm{MW}$, etc. have been announced. These areas are 
between islands with the maximum speed of $6.5 \mathrm{~m} / \mathrm{s}$ in Wooldolmok. The current speed is accelerated along narrow channels in between islands creating abundant energy potential. Before any planning of tidal farm, it is important to understand the energy estimation of the regions of interest. The tidal current farm projects in Korea are summarized in Table 1. There are several assessment methods introduced by IEA (International Energy Agency), IRENA (International Renewable Energy Agency), NREL (National Renewable Energy Laboratory), EU ERENE (European Community for Renewable Energy), Bonn University, DLR (German Aerospace Center), etc. Even these known methods have some sort of similarity, there are different definitions and classifications among them. In this paper, the four-step energy potentials are defined and introduced as theoretical, geographical, technical and market potentials. The tidal current assessment procedure is introduced and also a case study of tidal current power assessment in western coastal region, South Korea is explained.

\section{Resource Assessment Method}

Many researchers have studied the tidal energy assessment recently. In UK, the Pentland Firth and Orkney Islands, in Canada, Bay of Fundy and in Korea, Incheon and Jeolla Province are considered to be the suitable and commercially exploitable sites for tidal current power farm. Resource assessments for these regions have been undertaken in the past and the interaction effect in the multi-arrangement of tidal devices has been published by Jo et al. [1]. The related resource assessment papers have been published by Venugopal and Nemalidinne [2], Easton et al. [3], Baston and Harris [4], Karasten et al. [5].

For the Orkney and Pentland regions, a wave and tidal flow coupled model has been introduced by Venugopal and Nemalidinne [2]. The Gulf Stream energy modeling has been conducted by and Leaman et al. [6] to estimate the ocean current resource. The PDD (probability density distribution) of ocean current
Table 1 Tidal current farm projects in Korea.

\begin{tabular}{llll}
\hline Title & $\begin{array}{l}\text { Capacity } \\
\text { (MW) }\end{array}$ & Period & Status \\
\hline $\begin{array}{l}\text { Incheon TCP (tidal } \\
\text { current power) farm }\end{array}$ & 200 & $2012-2016$ & $\begin{array}{l}\text { Pre-feasibility } \\
\text { study }\end{array}$ \\
Shinan TCP farm & 260 & $2012-2016$ & $\begin{array}{l}\text { Pre-feasibility } \\
\text { study }\end{array}$ \\
Wando TCP farm & 300 & 2015 & Postponed \\
$\begin{array}{l}\text { Wooldolmok TCP } \\
\text { farm }\end{array}$ & 50 & 2018 & Delayed \\
$\begin{array}{l}\text { Daebang TCP farm } \\
\text { Maenggol TCP farm }\end{array}$ & 250 & From 2011 Planned \\
Jangjook TCP farm & 150 & 2018 & Planned \\
\hline
\end{tabular}

speed has been used to predict the power density and eventually the ocean energy.

However, the most of previously published papers are the theoretical approaches modeling the entire energy potential of the sites of interest. Generally, the energy resource assessment can be defined more specific into four to five categories from the theoretical potential to economic potential. The definition of energy assessment has been introduced by many organizations. IEA has defined as four steps: theoretical, technical, realizable and economic. Table 2 summarizes the potential definitions by several research groups. They have defined three to five energy potentials.

Evaluating the announced energy potential definitions, the four potential steps are determined and applied in the tidal current energy assessment in Korea; theoretical, geographical, technical and market potentials (Fig. 1).

Theoretical potential is the total natural energy existed in the region that can be determined as per the environmental conditions of the area of interest. Basically, the larger area and stronger flow velocity produce the larger energy potential. Geographical potential can be calculated from the theoretical potential excluding the energy from the limited areas such as shipping channel, military zone, natural preserve area, fishing zone, port facility, too shallow and too deep areas, etc. The area used in geographical potential can be changed with the change of the coastal planning. Technical potential is defined as the energy 
Table 2 Energy potential definition.

\begin{tabular}{ll}
\hline Organization & Definition \\
\hline IEA & $\begin{array}{l}\text { Theoretical, technical, } \\
\text { realizable, economic } \\
\text { potentials } \\
\text { Theoretical, technical, } \\
\text { economic potentials } \\
\text { Resource, technical, } \\
\text { economic, market potentials } \\
\text { IRENA }\end{array}$ \\
Theoretical, technical, \\
economic potentials \\
ERENE & $\begin{array}{l}\text { Theoretical, geographical, } \\
\text { technical, economic, market } \\
\text { potentials } \\
\text { REN21 }\end{array}$ \\
Theoretical, available, \\
Network for the 21st century \\
Bonn University & $\begin{array}{l}\text { potentials } \\
\text { Theoretical, technical, } \\
\text { economic deployment, } \\
\text { demand } \\
\text { Theoretical, technical, } \\
\text { realistic, realizable potentials }\end{array}$ \\
\hline
\end{tabular}

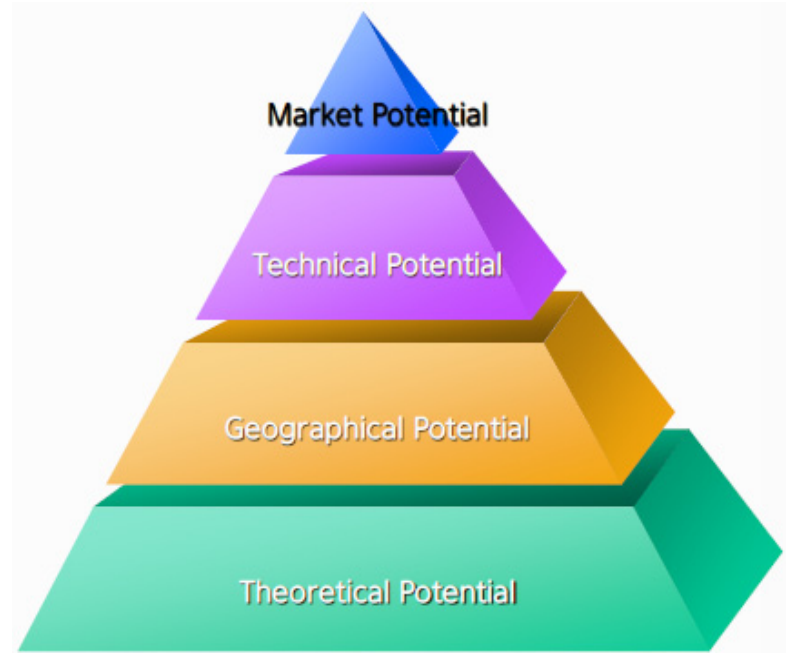

Fig. 1 Step of energy potential.

extracted in the area available for the device installation of the region. The energy extraction can be different from the assumptions of device type, its performance, system efficiency, interaction, power rate, etc. In this paper, the assumptions used in the technical tidal energy assessment are explained. Market potential is the practical energy assessment that can be realized with the financially feasibility considering the SMP (standard market price) of electricity and any compensation rate given from the government based on FIT (feed-in tariff) or RPS (renewable portfolio standard) policies.
Theoretical potential can be calculated based on API (averaged power intercepted) $\left(\mathrm{MW} / \mathrm{km}^{2}\right)$, which has been applied in wind power potential calculation as below:

$$
A P I=P D \cdot \frac{A}{A_{C T}}
$$

where, $P D$ - power density, $A$ - turbine area $\left(\pi D^{2} / 4\right)$ $\left.\mathrm{m}^{2}\right), D$-rotor diameter, $A_{C T}$-occupied area by current device.

\section{Energy Potential Calculation}

In order to calculate theoretical energy potential, the following assumptions are made:

- The boundary of the study is limited within EEZ (exclusive economic zone);

- API method is used in the potential estimation;

- The average flow velocity in mid depth is assumed as $95 \%$ of surface average velocity.

Geographical potential was estimated considering the restricted areas such as anchoring area, ship channel, military zone, fishing zone, ocean reserve area, ultimate preserve area, artificial reef zone, subsea pipeline and cable routes. The available area can be changed as per the future development of the region.

Technical potential represents the energy that can be extracted from the device implementation. Technical energy amount can be increased as per the development of technologies. In this study, the starting velocity of 70 $\mathrm{cm} / \mathrm{s}$, system efficiency of $35 \%$, operation rate of $35 \%$ are assumed. Also the interaction effects of multi-arrayed devices are considered. At $2.5 \mathrm{~m} / \mathrm{s}$ flow velocity, the device can have the maximum power of 1 MW with $20 \mathrm{~m}$ rotor diameter. It is know that the flow velocity can be restored up to $90 \%$ when spaced more than 10 D. Fig. 2 shows the velocity deficit as per the gap between devices [7].

There are few terms in energy potential definition. IGC (installed generating capacity) (GW), is the maximum output of generators in farm can produce 


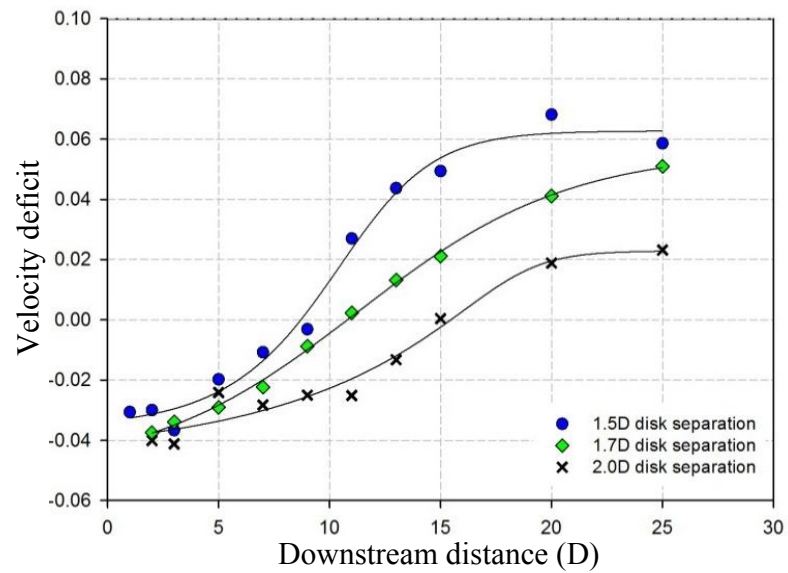

Fig. 2 Velocity deficit as per gap.

without exceeding design thermal limits. IGC can be calculated from Eq. (2):

$$
I G C=\frac{A P I_{a v g} \cdot A}{10^{3}}
$$

where, $A P I_{a v g}$ - average of API in area, $A$ - ocean area.

AEP (Annual Energy Production) (TWh/y), is the annual power generated from IGC and can be calculated from Eq. (3):

$$
A P E=\frac{I G C \times 24 \times 365 \times k_{u}}{10^{5}}
$$

where, $k_{u}-$ utilizable factor.

TOE (tonne of oil equivalent) $(1,000$ toe/y) is a unit of energy defined as the amount of energy released by burning one ton of crude oil. TOE is approximately 42 gigajoules, and the exact value is defined by a convention. TOE can be calculated from Eq. (4):

$$
T O E=\frac{A E P \times 10^{6}}{f}
$$

where, $f$-conversion factor $(=11.63$, at adapted IEA/SOEC (International Energy Agency and Statistical Office of the European Communities) definition).

The coastal line of Korea is divided into six zones along the coast line from the west to the east as shown in Fig. 3. The east coast above Region 6 is excluded in the resource assessment since it is known to be of low flow velocity.

After dividing the coastal areas into six zones, the ocean survey data were collected and analyzed in detail.
The average API was calculated as $24.69 \mathrm{MW} / \mathrm{km}^{2}$, IGC 1,931 GW, AEP 16,918 $\mathrm{TWh} / \mathrm{h}$ and TOE $1,455,017,000$ toe/y. Table 3 shows an example calculation of theoretical tidal energy potential for Region 3.

Geographical potential in Korea was calculated based on the available area from theoretical potential area. The restricted areas are as previous mentioned. The restricted area was calculated as $45,044 \mathrm{~km}^{2}$ which is about $56 \%$ of ocean area. The whole geographical potential in Korea was calculated as IGC of $685.2 \mathrm{GW}$, AEP of $6,002 \mathrm{TWh} / \mathrm{y}$ and TOE of 516,085,000 toe/y.

Technical potential can be estimated based on assumptions. The devices are installed in the available areas which is the same as the geographical potential area. The minimum start up velocity of $0.7 \mathrm{~m} / \mathrm{s}$, operation rate of $30 \%$ and system efficiency of $35 \%$ are applied to estimate the technical potential of the zones

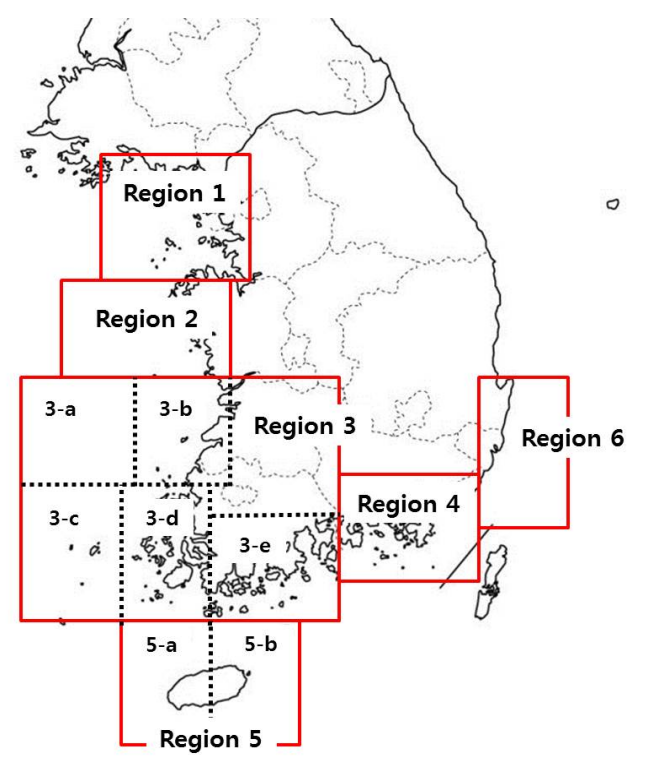

Fig. 3 The six zones for tidal energy assessment.

Table 3 Theoretical tidal energy potential in Korea.

\begin{tabular}{llllll}
\hline Region & $\begin{array}{l}\text { Averaged } \\
\text { API } \\
\left(\mathrm{MW} / \mathrm{km}^{2}\right)\end{array}$ & $\begin{array}{l}\text { Area } \\
\left(\mathrm{km}^{2}\right)\end{array}$ & $\begin{array}{l}\text { IGC } \\
(\mathrm{GW})\end{array}$ & $\begin{array}{l}\text { AEP } \\
(\mathrm{TWh} / \mathrm{y})\end{array}$ & $\begin{array}{l}\text { TOE } \\
(1,000 \text { toe/y })\end{array}$ \\
\hline $3-\mathrm{a}$ & 9.91 & 8,492 & 84.1 & 737 & 63,401 \\
$3-\mathrm{b}$ & 19.33 & 7,252 & 140.2 & 1,228 & 105,585 \\
$3-\mathrm{c}$ & 28.04 & 10,004 & 280.5 & 2,457 & 211,317 \\
$3-\mathrm{d}$ & 72.58 & 5,409 & 392.5 & 3,439 & 295,696 \\
$3-\mathrm{e}$ & 13.44 & 5,911 & 79.4 & 696 & 59,820 \\
\hline
\end{tabular}


of interest. The whole technical potential in Korea was calculated as IGC of $173.4 \mathrm{GW}$, AEP of $456 \mathrm{TWh} / \mathrm{y}$ and TOE of 39,183,000 toe/y.

However, market potential was not able to be conducted since the compensation rate for tidal current energy has not been determined by the government yet. Without the government compensation rate, it is not financially feasible and market potential will be calculated negative.

Tidal current farm planning is conducted in order to select the tidal farm area and there are certain procedures in general to understand the optimum conditions. First, the strong flow velocity is to be present in the region. The next step is to conduct a numerical modelling of the flow velocity in the region. Fig. 4 shows an example location showing the flow velocity distribution.

In the numerical simulation of flow velocity of the region of interest, the possible farm areas can be pre-determined. The farm area should have strong flow velocity first and be free from ship navigation channel, subsea obstacles, preserve zone, etc. Also it is important that, the area is not too far from the shore for grid connection and subsea cable connection. Fig. 5 shows an example of preliminary tidal farm areas.

After considering the preliminary tidal farm areas, a simple evaluation study can be done to choose the best area. The comparison factors are flow velocity, quantity of device, device size, possible power production rate, distance to the shore, construction method, grid connection, etc.

The arrangement of device should consider the interaction effect between devices. As the gap between devices increase, the less power loss from the downstream wake. It is know that the gap is to be more than $10 \mathrm{D}$ in general not to be much affected from the upstream device. However, if the area is large enough, it is recommended to have more than $20 \mathrm{D}$ gaps. Also the bottom and surface clearance are to be considered in the farm selection. Even there is no clear guideline on these, the $1 \mathrm{D}$ bottom and $0.5 \mathrm{D}$ surface clearances

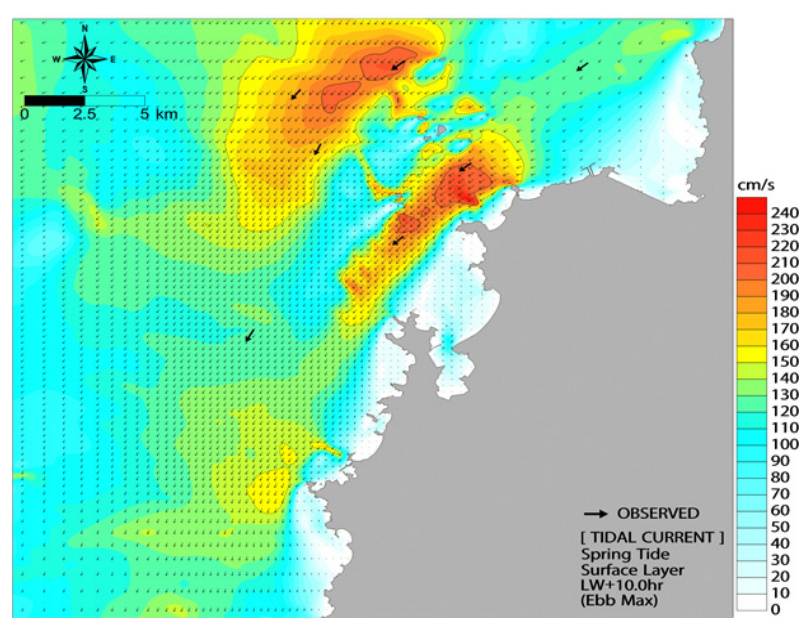

Fig. 4 Flow velocity distribution of an example area.

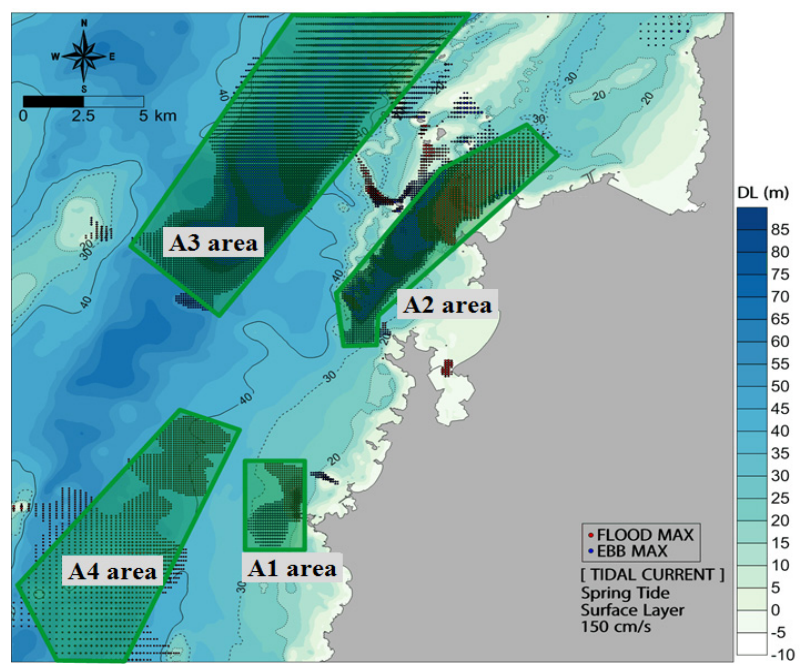

Fig. 5 Preliminary tidal farm areas as an example.

are applied in the example site. The wave height on the surface can effect on the clearance determination. The power generation production rate is to be calculated for each unit located in the specific velocity distribution spot. The total power production can be estimated by adding up all power rates from the units.

There are two types in tidal current device in general: HAT (horizontal axis turbine) and VAT (vertical axis turbine) as per turbine axis direction. There are good and bad sides for both types. However, most of devices being tested in the ocean for commercialization are HAT type. It is known that HAT has better efficiency than VAT. To support the device against external loadings, there are three types of foundation methods: pile fixed, GBS (gravity base structure) and mooring. 
The mono pile foundation has been applied widely to fix the turbine structure in relatively shallow water. However, if it is more than $50 \mathrm{~m}$, the cost of installation would be very high and occupy a great capital potion. Most of high current region has been surveyed as with rock seabed and needs drilling and grouting construction. The time window for construction in the high current region is very limited and the special work vessels are also to be mobilized. As water depth increases, the pile foundation cost gets much higher and this would impact to the economic feasibility of tidal current project. The mooring foundation has been proposed by a few developers like Nautricity, Scotland and Ocean Space, Inc., Korea. The big advantages of mooring foundation are the quick and simple installation and cost effective expense. However, it is important to reduce the excursion range and to keep vertical/horizontal positioning against strong current. Nautricity tries to resolve this problem by attaching a buoy to the mooring line by providing a vertical tension. The gaps between devices in multi-arrangement in the tidal farm should consider the larger excursion of mooring system together with accessibility of maintenance vessel.

GBS is one of foundation methods to secure the tidal device against strong current. To apply this type, the seabed condition is to be studied first for leveling and stable placement. The material cost of foundation is generally higher than other foundation methods. The advantage of this concept is the cost saving in the installation. Therefore, the evaluation and comparison of the foundation method is to be performed before the adaptation.

Another suggestion for the tidal current device selection would be the system with simple concept. This is because that, the accessibility to the offshore site is very limited due to the availability of equipment, personnel, weather condition, etc. The system should be designed to minimize the time duration for installation, maintenance and repair. Also the system configuration and component should be of high reliable and also simple to repair in ocean environment. The failure rate of wind turbine is mostly due to the gear box as per the published statistics. Having very similar component and system configuration like wind turbine, the tidal device would experience the same situation. Recently the tidal device without gear box has been developed by a few manufacturers. Since the most tidal current potential areas have very distinct flow directions with strong current speed within certain attach angle range. The flow velocity shows relatively high during high and low tide period. To maximize the production rate, it is recommended to have yawing mechanism in the system to accommodate the attack angle change.

As per the device design concept, the appropriate repair method is to be applied. This can be developed to minimize the maintenance period with cost effective. The nacelle can be lifted along the vertical pile (s) like MCT (marine current turbine) SeaGen and Open Hydro device. In this concept, the vertical pile is to be exposed high enough above the sea level for device maintenance. The pile can be large diameter with large overturning moment against current, wave and wind. The system can be lifted up by a crane vessel that is the most commonly applied to many devices. The floating buoy lifting system by Inha University can lift the device by crane (Fig. 6). But there is no diver is required since the floating buoy on water surface has pad eyes for connection with the crane. The floating buoy has the navigation and warning lights. Also the monitoring signals regarding to the device, power production, rpm, temperature, position, etc. can be transmitted wirelessly to the onshore control room.

More advance of lifting system is introduced and model tested at various current speeds by Inha University as shown in Fig. 7 [8]. After demonstration in a CWC (circulating water channel) with various current speeds, this guide wire with cone ended can low the nacelle successful at the maximum current speed up to $4 \mathrm{~m} / \mathrm{s}$.

Using the buoyance in ballasting tubular, the device can be lifted to the surface from underwater as shown in Fig. 8. 

in Western Coastal Region, South Korea

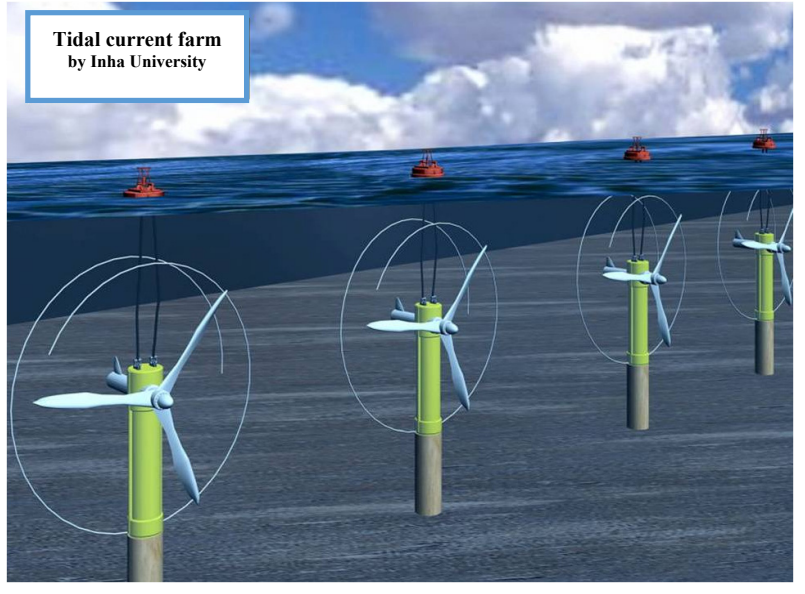

Fig. 6 Floating buoy lifting system.

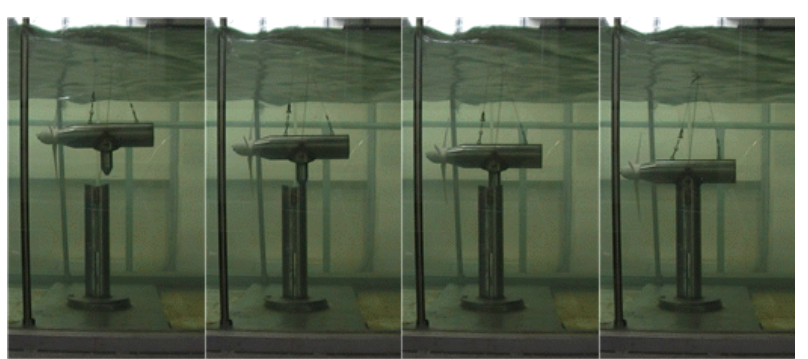

Fig. 7 Guide wire lifting system.

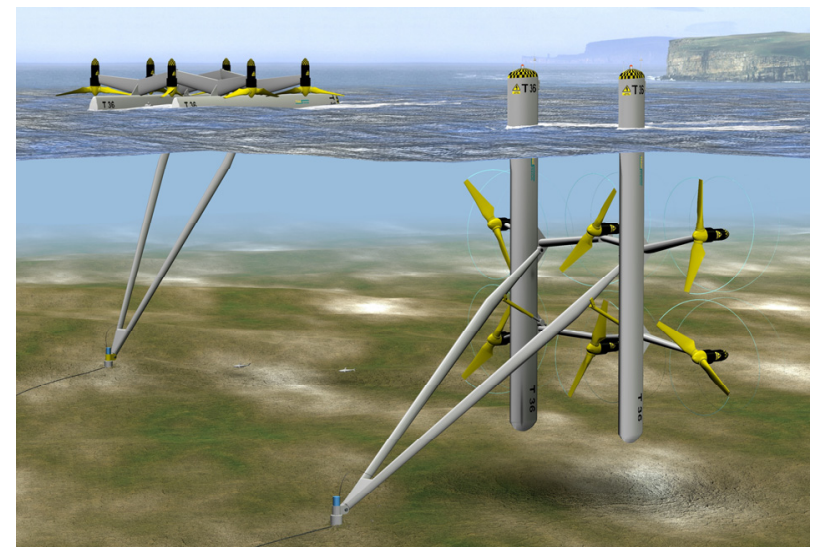

Fig. 8 Lifting device by buoyance introduced by Tidal Stream.

For multi-arrayed small scale tidal devices, it is very effective to have a module having ballasting control as shown in Fig. 9. This system has been designed and tested by Inha University successfully. Depending on the number of device and its size, the module can accommodate the devices. The module can lifted to the surface for repair and maintenance and lower down by filling water in the ballast tanks. This concept can be of high cost saving in operation of tidal turbines.
The power transmission from the tidal current farm can be either HVAC (high voltage alternating current) system or HVDC (high voltage direct current) system depending on the grid connection distance as shown in Fig. 10. HVAC can be effective method being effective or boosting voltage for relatively short distance. HVDC is known to be effective as the connecting subsea distance is more than $50 \mathrm{~km}$ long.

To collect the power from unit device, CEM (cable end manifold) should be used. There are two CEM
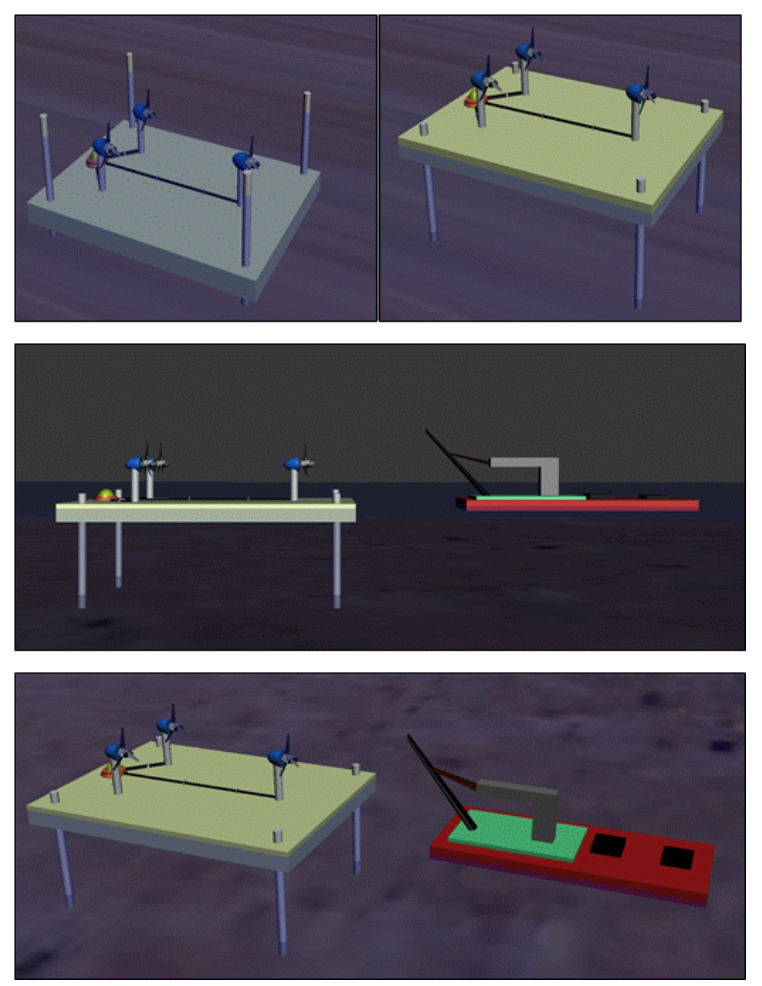

Fig. 9 Multi-arrayed tidal device module.

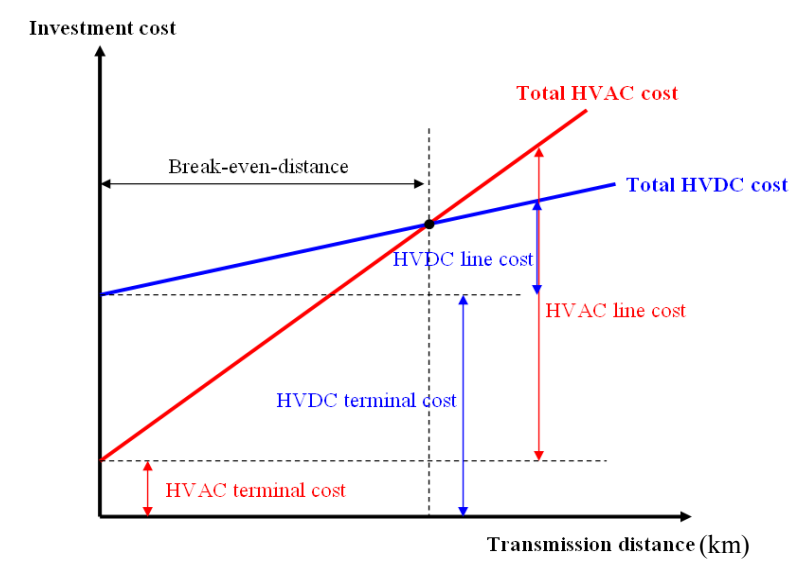

Fig. 10 Cost vs. distance of HVAC and HVDC. 


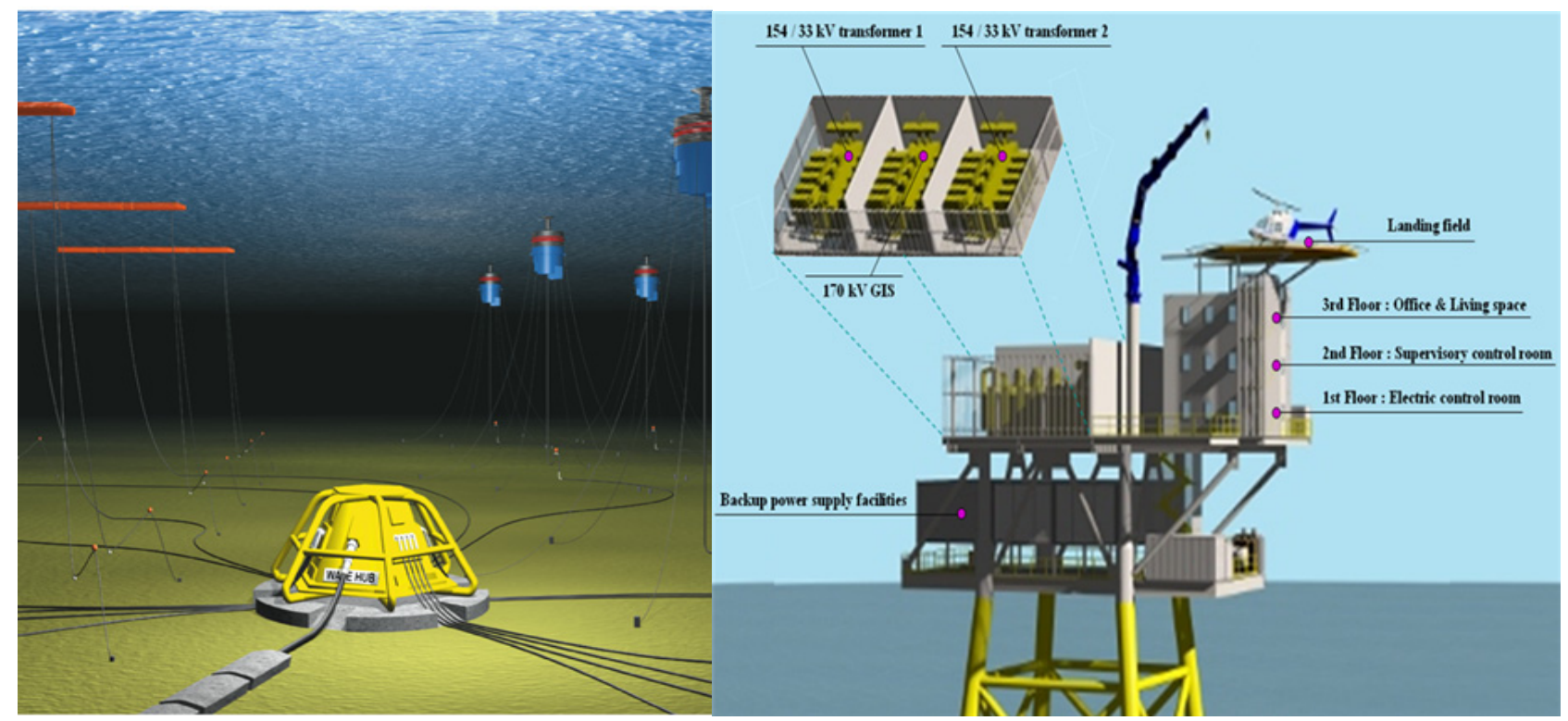

Fig. 11 Subsea CEM and platform CEM.

systems; subsea CEM and platform CEM as shown in Fig. 11. The subsea CEM is relatively high cost and difficult to maintenance. But the platform CEM can hold many power cables from unit devices and accommodate monitoring facilities together with SCADA (supervisory control and data acquisition) system, office area, helideck, etc. Should there are only few devices in the site, the subsea CEM can be used. But as there are many devices in the farm, the platform CEM can be effectively considered.

\section{Conclusions}

The four potential steps that can be applied in the determination of resource assessment are defined and introduced with detail procedures which are theoretical, geographical, technical and market potential. Theoretical potential is the total natural energy in the region as per the site environmental conditions. geographical potential is calculated from theoretical potential excluding the area which can not apply the tidal current device. Technical potential is defined as the energy extracted through tidal current device in the area of geographical potential. Market potential is the practical energy assessment that can be realized with the financially feasibility.
To calculate the resource assessment, the Korean Peninsula is divided as six regions. Theoretical potential of the coastal regions of Korea is estimated as averaged API of $24.69 \mathrm{MW} / \mathrm{km}^{2}$, IGC of $1,931 \mathrm{GW}$, APE of 16,918 TWh/y and TOE of 1,455,017,000 toe/y. Geographical potential was calculated excluding 56\% limited area of theoretical potential and the IGC is calculated as $685.2 \mathrm{GW}$, AEP 6,002 TWh/y and TOE $516,085,000$ toe/y. Technical potential was calculated considering the minimum start up velocity of $0.7 \mathrm{~m} / \mathrm{s}$, operating rate of $30 \%$ and system efficiency of $35 \%$. The results are IGC of $173.4 \mathrm{GW}$, AEP of $456 \mathrm{TWh} / \mathrm{y}$ and TOE of 39,183,000 TOE/y.

Tidal current farm planning in Korea was introduced showing the selection steps from site survey, device selection, support system, placement of device, grid connection and maintenance scheme. Since the financial feasibility is dependent on many factors, the optimization of site and system selection is to be done in the determination of tidal current farm site.

\section{Acknowledgments}

This work was supported by the New \& Renewable Energy Core Technology Program of the (KETEP 
Korea Institute of Energy Technology Evaluation and Planning), granted financial resource from the Ministry of Trade, Industry \& Energy, Republic of Korea. (20133030000260).

\section{References}

[1] Jo, C. H., Hwang, S. J., Lee, J. H., and Lee, K. H. 2013. "Design Procedure and Performance Estimation of Tidal Current Power System." In Proceedings of the 7th International Conference on APAC2013 (Asian and Pacific Coasts), 873-6.

[2] Venugopal, V., and Nemalidinne, R. 2014. "Maine Energy Resource Assessment for Orkney and Pentland Waters with a Coupled Wave and Tidal Flow Model.” Presented at the ASME (America Society of Mechanical Engineers) 2014 33rd International Conference on Ocean, OMAE (Offshore and Arctic Engineering) 2014, California, USA.

[3] Easton, M. C., Woolf, D. K., and Bowyer, P. A. 2012. "The Dynamics of an Energetic Tidal Channel, the Pentland Firth, Scotland." Cont. Shelf Res. 48: 50-60.
[4] Baston, S., and Harris, R. 2011. "Modelling the Hydrodynamic Characteristics of Tidal Flow in the Pentland Firth." Presented at the 9th European Wave and Tidal Energy Conference, Southampton, UK.

[5] Karasten, R. H., McMillan, J. M., Lickley, M. J., and Haynes, R. D. 2008. "Assessment of Tidal Current Energy in the Minas Passage, Bay of Fundy." Journal of Power and Energy 222 (5): 493-507.

[6] Leaman, K. D., Johns, E., and Rossby, T. 1989. “The Average Distribution of Colume Transport and Potential Vorticity with Temperature at Three Sections across the Gulf Stream." Journal of Physical Oceanography 19 (1): 36-51.

[7] Myers, L. E., Keogh, B., and Bahaj, A. S. 2011. "Layout Optimisation of 1st-Generation Tidal Energy Arrays." Presented at the EWTEC (European Wave and Tidal Energy Conference) 2011, Southampton, UK.

[8] Jo, C. H., Su-Jin, L. J., and Lee, K. 2014. "Maintenance Schemes for Tidal Current Power System Using Lifting Device." In Proceedings of the 2014 Korean Association of Ocean Science and Technology Societies Joint Symposium, 2487. 